\title{
Effect of an Educational Module on Knowledge, Symptoms Severity and Quality of Life in Patients with Irritable Bowel Syndrome
}

\author{
Asmaa Ghareeb Mohamed ${ }^{1}$; Fatma Mohmmed Abouelala ${ }^{2}$ \& Fatma Mohamed Elesawy $^{3}$ \\ 1. Assistant professor of community health nursing, Faculty of nursing, Assiut University \\ 2. Lecturer of medical surgical nursing, Faculty of nursing, Kafrelsheikh University \\ 3. Lecturer of medical surgical nursing, Faculty of nursing, South Vally University
}

\begin{abstract}
Background: Irritable bowel syndrome is a widespread digestive disorder that is characterized by diarrhea and/or constipation, bloating, and associated with abdominal pain. This disorder can seriously display individuals and quality of life. Aim: The aim was to evaluate the effect of an educational module on knowledge level, symptoms severity \& quality of life in patients with irritable bowel syndrome. Method: Quasi-experimental research design (pre posttest and follow up) was applied. Fifty adult IBS patients (Rome criteria) were prospectively enrolled in this study in out-patient clinic at south valley University Hospital. Demographic, clinical data and knowledge were recorded. Patient's quality of life subscales (dysphoria, interference with activity, body image, health worry, food avoidance, social reaction, sexual concerns, \& relationships). and disease severity also were assessed. Results: The results revealed that total mean knowledge scores of patients' post-educational intervention were improved than that of their pre-scores, increase the mean scores of quality of life subscales post and follow-up educational intervention compared to pre educational intervention with highly statistically significant differences between them at $\mathrm{p}<0.001$. Also, this study showed that $60.0 \%$ of the studied patients had moderate symptoms pre educational intervention compared with $36.0 \%$ post and $42.0 \%$ in follow-up phase with a highly significant difference between them $(\mathrm{P}<$ 0.01). Conclusion \& Recommendations: The educational module is effective in enhancing knowledge, quality of life, and decreasing the symptoms severity in patients with irritable bowel syndrome. Continuous patient education must be planned regularly to control disease symptoms and improve quality of life.
\end{abstract}

\section{Keywords: Educational Module, Irritable Bowel Syndrome, Knowledge, Symptoms \& Quality of life.}

\section{Introduction:}

Irritable bowel syndrome (IBS) is a common digestive disorder, and more popular second cause of absent from work after the common flu (Defrees \& Bailey 2017). This syndrome is a major health problem globally (Dalrymple \& Bullock, 2008). The prevalence varied widely among countries, and even after similar diagnostic criteria was carrying out, this variation persisted even the same methodology was carried out in the studies (Oka et al., 2020).

The prevalence of IBS distinct from 5.7 to $34 \%$ over the world. The occurrence was higher in women than in men with a ratio of $2: 1$, and the climax of the syndrome often began in early adulthood (Lovell, \& Ford 2012). In the same line, a study that was conducted in Egypt by (Elhosseiny et al., 2019) who found that the recurrence rate of IBS was $31.7 \%$ with a higher prevalence among women and among clients who had family history of IBS.

The burden that resulting from IBS is large enough to donate a significant decrease in QoL. It especially affects social and emotional performance which leads to depression, and an increase in absenteeism rates from school and work stations is also observed. This disorder also affects physical functions, which may be worse than both diabetes and high blood pressure (Alsuwailm et al., 2017).

Irritable Bowel Syndrome is adding a large financial burden due to the direct and indirect healthcare expenses. The use of health care facilities is more common in patients with IBS when compared with non- IBS patients, in terms of more regular clinic visits, extra diagnostic testing, frequent use of medications, and elevated rates of unnecessary operations. (Hulisz, 2004).

The pathogenesis of IBS has multiple factors, such as gene influence, food intolerance, changes in GI bacteria, activation of intestinal immunity, increased bowel permeability and hypersensitivity, and alteration in the neuroendocrine system of the bowel (Imperatore et al., 2016).

The most important step to make a positive diagnosis of IBS is the change in stool characteristics and frequency of defecation, so these changes allowed IBS to be categorized into subcategories based on the pattern of stool. They are dominant diarrhea (IBS-D), dominant constipation (IBS-C), or fluctuation between diarrhea and constipation which classify as mix (IBS-M) (Walker et al., 2014). 
The diagnosis of IBS is based on various diagnostic criteria as, Manning, and Rome criteria, according to the Rome Foundation criteria, there are 4 diverse versions Rome I, II, III and IV. The Rome criteria is intended to classify functional gastrointestinal disorders that depend on symptoms for diagnosis (Drossman, 2016). Irritable bowel syndrome is a symptom-based condition, so it aims to treat symptoms as diarrhea or constipation, pain, bloating, and or cramping, based on the subcategories of IBS, symptoms may be treated by using a combination of pharmacological and non-pharmacological treatments (Occhipinti \& Smith., 2012).

Lifestyle and diet management are sometimes considered prior to drug therapy. Lack of exercises, lack of food intake, lack intake of fiber diet, and lack of appropriate time to defecate, they can contribute to developing of IBS, specially (IBS-C), therefore, increasing fibers in diet and performing regular exercise may benefit IBS patients who suffer from constipation (Hoveyda et al., 2009). On the other hand, excessive consumption of indigestible carbohydrates, caffeine, and high lactose have been discovered to lead to (IBS-D). Therefore, a stepwise food restriction strategy may be effective if the symptoms are relatively mild (Austin et al., 2009). Strong evidence exists for patients with IBS to support that the use of a number of psychotherapeutic interventions. The best evidence-based approaches are cognitive-behavioral therapy, hypnosis, and mindfulness-based therapies (Ballou, \& Keefer, 2017).

Health education is an important need for patients with chronic disease, and can be defined as providing clinical information to support patients and care provider to solve issues arising from chronic condition (Halpert et al., 2008). In caring for patients with IBS, nurse specialty training plays an important role in caring for patients with IBS by providing teaching to patients and their relatives to improve QoL and knowledge, screen response to treatment, and inform the health care team about the patients' condition (Patel \& Shackelford., 2020).

In the same line (Coutts, 2019), concluded that there are many available pharmacological treatment that can alleviate the symptoms of IBS and many nursing interventions that can treat the underlying factors of IBS, nursing interventions emphasis on working with patients to make dietary changes, alleviate the underlying factors that lead to IBS, and relieve the tension and anxiety that may frequently induced by this disorder.

\section{Significance of the Study}

Patients with IBS have poor QOL compared to the general population and people with other chronic diseases such as rheumatoid arthritis. Living with IBS may cause an individual to experience additional extra gastrointestinal symptoms such as headache, sleep disturbance, menstrual symptoms, urinary symptoms, chronic fatigue syndrome, fibromyalgia, and weight loss (Sperber \& Dekel, 2010).

Incorrect and lack of information about IBS are widespread, especially regarding the causes and prognosis of the disease. Providing correct information about the disease reduces the symptoms as well as the anxiety associated with the disease. Topics of interest to those patients include dietary modifications, the causes of IBS, coping strategies to reduce symptoms, and how to prevent IBS attacks (Dorn, et al.,2015).

Therefore, a study to evaluate the effect of an educational module on knowledge, symptoms severity and QoL in the Egyptian population who experience IBS is needed. Providing individual education combined with non-pharmacological therapy could contribute to alleviation/remission of symptoms and improve QOL of patients with IBS.

Aim of the study:

This study aimed to evaluate the effect of an educational module on knowledge, symptoms severity and quality of life in patients with irritable bowel syndrome.

\section{Hypothesis:}

The following research hypotheses were formulated to achieve the aim of the study:

$\mathbf{H}_{1}$ : The patients' knowledge scores regarding to irritable bowel syndrome will be higher post implementation of the educational module than their pre- implementation scores.

$\mathbf{H}_{2}$ : The patients' symptoms severity level post implementation of the educational module will decrease compared to their pre-implementation.

$\mathbf{H}_{\mathbf{3}}$ : The patients' quality of life scores will be higher post implementation of the educational module than their pre-implementation scores.

\section{Subjects \& Method: \\ Research design:}

A quasi experimental research design (pre-posttest and follow up) was used to conduct this study.

setting:

This study was conducted in outpatient clinic at South valley University Hospital.

\section{Subjects}

A purposive sample of 50 adult subjects were recruited in the current study. For sample size estimation, the $\mathrm{G}$ power software program was used. The inclusion criteria of the subjects were both gender, and aged 18 to 60 years who selected according to Rome Criteria IV (Lacy, \& Patel, 
2017), which based on the following criteria; frequent abdominal pain that has occurred at least once a week in the past three months that has been associated with two or more of the following criteria; relief after elimination, change in stool frequency and or change in the form of the stool. Symptoms must have developed at least 6 months previous to diagnosis, and symptoms must have occurred during the preceding three months. Patients who have previously been diagnosed with Crohn's, diverticulitis, peptic ulcer, ulcerative colitis, and colon cancer were excluded from this study.

\section{Tool for data collection:}

The following tool was utilized to collect data which comprised from the next parts

Part I: Patient's demographic characteristics data as age, sex, marital status, education, and occupation.

Part II: Patient's clinical data as smoking habit, duration of illness, type of irritable bowel syndrome.

Part III: Patient's knowledge questionnaire sheet about IBS. This part was developed by the researchers after reviewing of the recent literature. It comprised of (53) questions. The patient's knowledge score was considered satisfactory if the percentage was $60 \%$ or higher and unsatisfactory if it was less than $60 \%$.

Tool validity: The study tool was offered to a jury composed of five experts in the specialty of medical surgical nursing and internal medicine to test the content validity. They were asked to judge the completeness and accuracy of the content of the tools and the necessary modifications were done.

Part IV: IBS-QOL questionnaire it was adopted from (Drossman, et al., 2000). It consists of 34 items ranging "Not at all" to "A lot" or "Extremely" with five choice Likert-type response items and eight separate subscales as dysphoria (eight items), interference with activity (seven items), body image (four items), health worry (three items), food avoidance (three items), social reaction (four items), sexual issues (two items) and relationships (three items). Scores obtained are transformed on the IBSQOL into 0 to 100 points, converting the severity of symptoms to a scale varying from 0-100. Higher scores mean that HR-QOL is good. The reliability was 0.80 .

Part V: Irritable bowel syndrome - severity symptom scale IBS SSS: It was adopted from (Francis, et al.,1997). It is used to determine the severity of the symptoms. The instrument consisted of five questions using the Visual Analogue Scale to estimate pain intensity, pain frequency, the severity of flatulence, satisfaction with defecation, as well as effect of IBS on the quality of life. The minimum and maximum scores respectively were 0 and 500. More severe symptoms were shown by higher ratings. The scores were categorized into three parts according to the data obtained: mild symptoms (75-175), medium (176-300) and, extreme (301-500). The reliability was 0.81 .

Pilot study:

A pilot study was performed on $10 \%$ of the patients for the clarity and applicability of the tool; these patients were not included in the study sample.

\section{Procedure}

- Official agreement was obtained to conduct the study from the responsible authorities of Qena University hospital. The research was carried out over a period of six months from September 2019 to March 2020.

- An outpatient exploratory visit was performed to estimate patient frequency rate and appropriate time to collect the data. Besides, personal communication was made with the nurses and the doctor to clarify the nature of the research and get the best possible cooperation.

- After clarifying the nature and purpose of the study and obtaining their approval, patients who met the study criteria were included in the study.

- Data were collected from patients using the study tool (pre-test) via face- to- face interview; it was taken about 20-30 minutes.

- The objectives and content of the educational module were established based on a review of related literature as well as patients' educational needs.

- Educational module sessions were included the following; knowledge about IBS such as anatomy and physiology of the colon, definition of IBS, causes, signs, and symptoms, treatment plan which include (drug therapy, diet, exercises, and relaxation technique, as well as complication and follow-up care.

- Educational module sessions were offered to groups consisting of 2-5 patients and performed on the basis of specific needs and level of understanding through lectures, discussions, demonstration and redemonstration.

- An education module conducted in 3 sessions, each session lasted approximately 30-45 minutes, on the morning shift twice a week.

- Patients were asked questions relevant to the subjects addressed in the previous session before beginning a new session to ensure that they remembered the instructions given; missing or vague points were re-emphasized by the researcher.

- A copy from the educational booklet was given to each patient, it was presented in an Arabic language. 
- The effect of the educational module was evaluated after 1 month (post), and after 2 months (followup).

- Coordination with the patients to follow up when they go to outpatient clinics. Also followed them by the phone.

\section{Ethical consideration:}

Patients' consent was obtained after clarifying the aim of the study and announcing them that they could withdraw at any stage of the study without any responsibility.
Statistical analysis:

The data obtained were coded and tabulated; (SPSS) version 25 was used. By using frequencies, percentages, means, and standard deviations descriptive analysis was carried out. Using chisquare for comparison between two qualitative variables, and the Wilcoxon ranks test was also used. For assessment of the inter-relationships between qualitative variables Pearson correlation was used. $\mathrm{P}$-value $=\leq 0.05$.

\section{Results}

Table (1): Demographic and clinical data of studied subjects $(\mathrm{N}=50)$.

\begin{tabular}{|c|c|c|}
\hline Items & No. (50) & $\%$ \\
\hline $\begin{array}{l}\text { Age (Years): } \\
\text { - } \quad \text { Less than } 30 \\
\text { - } 30 \text { to } 50 \\
\text { - } \quad \text { Mor than } 50\end{array}$ & $\begin{array}{c}20 \\
23 \\
7\end{array}$ & $\begin{array}{l}40.0 \\
46.0 \\
14.0\end{array}$ \\
\hline $\begin{array}{l}\text { Range } \\
\text { Mean } \pm \text { SD }\end{array}$ & \multicolumn{2}{|c|}{$\begin{array}{c}18-57 \\
33.8 \pm 11.1 \\
\end{array}$} \\
\hline $\begin{aligned} \text { Sex: } & \\
& \text { - } \\
& \text { Male } \\
& \text { Female }\end{aligned}$ & $\begin{array}{l}21 \\
29\end{array}$ & $\begin{array}{l}42.0 \\
58.0\end{array}$ \\
\hline $\begin{array}{c}\text { Marital status: } \\
\text { - Single } \\
\text { - Married } \\
\text { - Widow }\end{array}$ & $\begin{array}{c}11 \\
38 \\
1\end{array}$ & $\begin{array}{c}22.0 \\
76.0 \\
2.0\end{array}$ \\
\hline $\begin{array}{l}\text { Level of education } \\
\text { - Illiterate } \\
\text { - Reads and writes } \\
\text { - Basic education } \\
\text { - Secondary schools } \\
\text { - Higher education }\end{array}$ & $\begin{array}{c}2 \\
8 \\
6 \\
18 \\
16\end{array}$ & $\begin{array}{l}4.0 \\
16.0 \\
12.0 \\
36.0 \\
32.0\end{array}$ \\
\hline $\begin{array}{l}\text { Occupation: } \\
\bullet \text { Non-working } \\
\bullet \quad \text { Working }\end{array}$ & $\begin{array}{l}22 \\
28\end{array}$ & $\begin{array}{l}44.0 \\
56.0\end{array}$ \\
\hline $\begin{aligned} & \text { Smoking } \\
& \text { - } \\
& \text { - } \text { Passive smoker } \\
& \text { - } \text { Non-smoker }\end{aligned}$ & $\begin{array}{l}13 \\
9 \\
28\end{array}$ & $\begin{array}{c}26.0 \\
18.0 \\
56.0\end{array}$ \\
\hline $\begin{array}{c}\text { Duration of illness } \\
\text { • } \\
\text { • } \\
\end{array}$ & $\begin{array}{l}36 \\
14\end{array}$ & $\begin{array}{l}72.0 \\
28.0\end{array}$ \\
\hline $\begin{array}{c}\text { Family history } \\
\qquad \text { No } \\
\text { - } \quad \text { Yes }\end{array}$ & $\begin{array}{l}34 \\
16\end{array}$ & $\begin{array}{l}68.0 \\
32.0\end{array}$ \\
\hline $\begin{array}{cl}\text { Type of irritable bowel } \\
\text { - } & \text { Diarrhea } \\
\text { - } & \text { Constipation } \\
\text { - } & \text { Mixed }\end{array}$ & $\begin{array}{l}16 \\
20 \\
14\end{array}$ & $\begin{array}{l}32.0 \\
40.0 \\
28.0\end{array}$ \\
\hline
\end{tabular}


Table (2): The differences of subjects according to satisfactory level of knowledge regarding IBS pre, post and follow up phases of educational module $(\mathrm{N}=50)$.

\begin{tabular}{|c|c|c|c|c|c|c|c|c|}
\hline \multirow{3}{*}{$\begin{array}{c}\text { Satisfactory } \\
\text { Knowledge } \\
(60 \%+)\end{array}$} & \multicolumn{6}{|c|}{ Time } & \multirow{3}{*}{$\begin{array}{c}\chi^{2} \\
(\mathbf{P}) \\
\text { Pre-post }\end{array}$} & \multirow{3}{*}{$\begin{array}{c}\chi^{2} \\
(\mathbf{P}) \\
\text { Pre-FU }\end{array}$} \\
\hline & \multicolumn{2}{|c|}{ Pre } & \multicolumn{2}{|r|}{ Post } & \multicolumn{2}{|c|}{ FU } & & \\
\hline & No. & $\%$ & No. & $\%$ & No. & $\%$ & & \\
\hline \multicolumn{9}{|l|}{ General Knowledge about IBS: } \\
\hline Anatomy \&physiology of colon & 3 & 6.0 & 38 & 76.0 & 36 & 72.0 & $50.641(<0.001 *)$ & $45.776(<0.001 *)$ \\
\hline - Definition of IBS & 4 & 8.0 & 39 & 78.0 & 40 & 80.0 & $49.980(<0.001 *)$ & $52.597(<0.001 *)$ \\
\hline - Causes IBS & 19 & 38.0 & 48 & 96.0 & 46 & 92.0 & $38.037(<0.001 *)$ & $32.044(<0.001 *)$ \\
\hline - Sing and symptoms & 10 & 20.0 & 43 & 86.0 & 42 & 84.0 & $43.777(<0.001 *)$ & $41.026(<0.001 *)$ \\
\hline - Diagnosis & 9 & 18.0 & 43 & 86.0 & 39 & 78.0 & $46.314(<0.001 *)$ & $36.085(<0.001 *)$ \\
\hline - Drug therapy & 5 & 10.0 & 44 & 88.0 & 41 & 82.0 & $60.864(<0.001 *)$ & $52.174(<0.001 *)$ \\
\hline - Complications & 6 & 12.0 & 43 & 86.0 & 41 & 82.0 & $54.782(<0.001 *)$ & $49.177(<0.001 *)$ \\
\hline \multicolumn{9}{|c|}{ Knowledge about Lifestyle Modification: } \\
\hline -Diet & 12 & 24.0 & 46 & 92.0 & 44 & 88.0 & $47.455(<0.001 *)$ & $41.558(<0.001 *)$ \\
\hline -Exercise \& relaxation technique & 0 & 0.0 & 41 & 82.0 & 38 & 76.0 & $69.492(<0.001 *)$ & $63.934(<0.001 *)$ \\
\hline -Herbal therapy & 14 & 28.0 & 48 & 96.0 & 48 & 96.0 & $49.66(<0.001 *)$ & $49.66(<0.001 *)$ \\
\hline -followup & 0 & 0.0 & 40 & 80.0 & 38 & 76.0 & $66.66(<0.001 *)$ & $61.290(<0.001 *)$ \\
\hline \multicolumn{9}{|l|}{$\begin{array}{l}\text { Total knowledge score regarding } \\
\text { IBS }\end{array}$} \\
\hline Unsatisfactory & 46 & 92.0 & 7 & 14.0 & 9 & 18.0 & \multirow{2}{*}{$61.060(<0.001 *$} & \multirow{2}{*}{$55.313\left(<0.001^{*}\right.$} \\
\hline Satisfactory & 4 & 8.0 & 43 & 86.0 & 41 & 82.0 & & \\
\hline Mean \pm SD & \multicolumn{2}{|c|}{$34.07 \pm 13.1$} & \multicolumn{2}{|c|}{$80.5 \pm 16.8$} & \multicolumn{2}{|c|}{$77.0 \pm 19.6$} & $Z: 6.157\left(<0.001^{*}\right)$ & $Z: 6.154(<0.001 *)$ \\
\hline
\end{tabular}

Table (3): The differences of subjects according to IBS symptoms severity pre, post and follow up phases of educational module $(\mathrm{N}=50)$.

\begin{tabular}{|c|c|c|c|c|c|c|c|c|}
\hline \multirow{3}{*}{$\begin{array}{l}\text { IBS symptoms } \\
\text { severity scale }\end{array}$} & \multicolumn{6}{|c|}{ Time } & \multirow{3}{*}{$\begin{array}{c}\chi^{2} \\
(\mathbf{P}) \\
\text { Pre-post }\end{array}$} & \multirow{3}{*}{$\begin{array}{l}\chi^{2} \\
(\mathbf{P}) \\
\text { Pre-FU }\end{array}$} \\
\hline & \multicolumn{2}{|c|}{ Pre } & \multicolumn{2}{|c|}{ Post } & \multicolumn{2}{|c|}{$\mathbf{F U}$} & & \\
\hline & No & $\%$ & No & $\%$ & No & $\%$ & & \\
\hline \multirow{4}{*}{$\begin{array}{l}\text { Mild }(75-175) \\
\text { Moderate }(176-300) \\
\text { Severe }(301-500) \\
\text { Mean } \pm \text { SD }\end{array}$} & 11 & 22.0 & 29 & 58.0 & 27 & 54.0 & \multirow[t]{3}{*}{$14.10(<0.001 *)$} & \multirow[t]{3}{*}{$11.716(<0.003 *)$} \\
\hline & 30 & 60.0 & 18 & 36.0 & 20 & 40.0 & & \\
\hline & 9 & 18.0 & 3 & 6.0 & 3 & 6.0 & & \\
\hline & \multicolumn{2}{|c|}{$220 \pm 69.80$} & \multicolumn{2}{|c|}{$125 \pm 75.24$} & \multicolumn{2}{|c|}{$126.14 \pm 71.09$} & $\mathrm{Z}: 6.147(<0.001 *)$ & $\mathrm{Z}: 6.144(<0.001 *)$ \\
\hline
\end{tabular}

Table (4): IBS-QOL subscales among patients throughout pre, post and follow up phases of educational module $(\mathbf{N}=\mathbf{5 0})$.

\begin{tabular}{|c|c|c|c|c|c|}
\hline \multirow{3}{*}{ IBS-QOL domains } & \multicolumn{3}{|c|}{ Time } & \multirow{3}{*}{$\begin{array}{c}\mathrm{Z} \\
(\mathrm{P}) \\
\text { Pre-post }\end{array}$} & \multirow{3}{*}{$\begin{array}{c}\mathbf{Z} \\
(\mathbf{P}) \\
\text { Pre-FU }\end{array}$} \\
\hline & Pre & Post & FU & & \\
\hline & Mean \pm SD & Mean \pm SD & Mean \pm SD & & \\
\hline Dysphoria & $44.7 \pm 11.6$ & $64.8 \pm 10.1$ & $73.5 \pm 14.6$ & $5.894\left(<0.001^{*}\right)$ & $6.049(<0.001 *)$ \\
\hline Interference with activity & $47.9 \pm 11.9$ & $69.1 \pm 8.6$ & $75.0 \pm 11.7$ & $6.041(<0.001 *)$ & $6.105(<0.001 *)$ \\
\hline Body image & $61.2 \pm 8.4$ & $70.7 \pm 6.8$ & $79.8 \pm 11.8$ & $5.020\left(<0.001^{*}\right)$ & $5.773(<0.001 *)$ \\
\hline Health worry & $49.8 \pm 17.2$ & $71.3 \pm 10.9$ & $81.5 \pm 15.9$ & $5.531(<0.001 *)$ & $5.885(<0.001 *)$ \\
\hline Food avoidance & $42.5 \pm 10.5$ & $63.5 \pm 9.9$ & $65.6 \pm 12.0$ & $5.947(<0.001 *)$ & $5.968(<0.001 *)$ \\
\hline Social reaction & $50.7 \pm 14.7$ & $69.0 \pm 10.4$ & $77.0 \pm 14.4$ & $5.594(<0.001 *)$ & $5.925(<0.001 *)$ \\
\hline Sexual & $76.2 \pm 15.6$ & $1.0 \pm 12.6$ & $83.0 \pm 15.3$ & $1.844(.065)$ & $2.353((019 *)$ \\
\hline Relationship & $61.3 \pm 11.0$ & $69.6 \pm 8.7$ & $80.6 \pm 14.5$ & $3.938(<0.001 *)$ & $5.317(<0.001 *)$ \\
\hline IBS-QOL Total & $51.6 \pm 6.0$ & $68.7 \pm 8.0$ & $76.1 \pm 11.5$ & $6.095(<0.001 *)$ & $6.094(<0.001 *)$ \\
\hline
\end{tabular}

Z: Wilcoxon test

$*$ significant at $P$ value $\leq 0.05$ 
Table (5): Correlation between patients' level of knowledge regarding irritable bowel syndrome and their IBS QOL score and IBS-SSS score throughout the study Phases ( $N=50)$

\begin{tabular}{|c|c|c|c|c|c|c|}
\hline \multirow[t]{2}{*}{ Items } & \multicolumn{2}{|c|}{$\begin{array}{l}\text { Total knowledge } \\
\text { scores Pre }\end{array}$} & \multicolumn{2}{|c|}{$\begin{array}{l}\text { Total knowledge } \\
\text { scores Post }\end{array}$} & \multicolumn{2}{|c|}{$\begin{array}{l}\text { Total knowledge } \\
\text { scores Follow-up }\end{array}$} \\
\hline & $\mathbf{R}$ & $\mathbf{P}$ & $\mathbf{R}$ & $\mathbf{P}$ & $\mathbf{R}$ & $\mathbf{P}$ \\
\hline IBS-QOL Pre & .804 & $<0.001^{*}$ & & & & \\
\hline IBS-QOL Post & & & .804 & $<0.001 *$ & & \\
\hline IBS-QOL Follow-up & & & & & .715 & $<0.001^{*}$ \\
\hline IBS-SSS Pre & $.628-$ & $<0.001^{*}$ & & & & \\
\hline IBS-SSS Post & & & $.515-$ & $<0.001^{*}$ & & \\
\hline IBS-SSS Follow-up & & & & & $.636-$ & $<0.001 *$ \\
\hline
\end{tabular}

$r$ : Pearson Correlation

*Significance at $p$ value $<0.05$

Table (6): Correlation between patients' IBSQOL score and IBS-SSS score throughout the study phases (N=50)

\begin{tabular}{|l|c|c|c|c|c|c|}
\hline \multirow{2}{*}{ Items } & \multicolumn{2}{c|}{ IBS-QOL Pre } & \multicolumn{2}{c|}{ IBS-QOL Post } & \multicolumn{2}{c|}{ IBS-QOL Follow-up } \\
\cline { 2 - 6 } & $\mathbf{R}$ & $\mathbf{P}$ & $\mathbf{R}$ & $\mathbf{P}$ & $\mathbf{R}$ & P \\
\hline IBS-SSS Pre & $.604-$ & $<0.001^{*}$ & & & & \\
\hline IBS-SSS Post & & & $.505-$ & $<0.001^{*}$ & & $<0.001^{*}$ \\
\hline IBS-SSS Follow-up & & & & & $.630-$ & *Significance at $p$ value $<0.05$ \\
\hline
\end{tabular}

Table (1): Shows around half of studied sample 46.0 $\%$ their age ranged between $30-50$ years; females represent more than half $58.0 \%$. Also, more than half $56 \%$ of the studied sample was working and nonsmoker. Regarding to duration of the disease, more than two thirds $72 \%$ suffering from IBS for less than five years. The most common type of IBS is constipation $40.0 \%$, followed by diarrhea $32.0 \%$, and then the mixed type $28.0 \%$.

Table (2): Shows that, increase level of satisfactory knowledge from $8.0 \%, 86.0 \%$, to $82.0 \%$ in pre, post, and follow-up implementation of educational module respectively. There was a highly statistically significant difference between pre/post and pre/follow up phases $(\mathrm{p}<0.01)$. Finally, it was observed that total mean knowledge scores of patient's post-educational module was improved than that of their pre- educational module scores, and there were statistically significant differences between pre/post, and pre/follow-up regarding patient knowledge related to IBS $(\mathrm{P}<0.001 *)$.

Table (3): Shows the differences between severities of symptoms among the studied patients pre, post and follow-up educational intervention using IBS symptoms severity scale. It reveals that $60.0 \%$ of the studied sample had moderate symptoms pre implementation of educational module compared with $36.0 \%$ post and $42.0 \%$ in follow up with highly significant difference between them $(\mathrm{P}<0.01)$. Moreover, there is a highly statistically significant difference between the mean scores of symptoms severity for IBS patient's pre, post and follow up educational intervention $(\mathrm{P}<0.01)$.
Table (4): Shows the difference among IBS-QOL subscales pre, post and follow-up implementation of educational module. It reveals that the mean scores of IBS-QOL subscales were increased post and followup educational implementation compared to pre educational implementation with highly statistically significant differences between them at $\mathrm{p}<0.001$

Table (5): Showed a significant positive correlation between knowledge level and IBS-QOL in post and follow-up phases of implementation of educational module $(\mathrm{p}<0.05)$. There was significant negative correlation between level of knowledge and IBS-SSS in pre, post and follow-up phases $(\mathrm{p}<0.05)$.

Table (6): This table showed that, there was significant negative correlation between IBS-QOL score and IBS-SSS in pre, post and follow-up phases of educational module $(\mathrm{p}<0.05)$.

\section{Discussion:}

Irritable bowel syndrome is a common disorder that places a heavy burden on communities, healthcare, and all over the world (Bradley et al., 2018). Additional impaired of QoL in patients with IBS when compared with the other population (Yu, et al., 2014). Little is known about concerns of the patients with IBS or their actual level of knowledge regarding the syndrome (Weiser et al., 2008).

This study found out that around one third of patients $(32.0 \%)$ had family history of IBS, this result near to the findings by (Abd Elaziz et al., 2019) who reported that around half of IBS patients had a family history of IBS. 
It has been found that majority of studied sample had duration of disease less than 5 years and $28 \%$ had duration of illness more than 5 years. This in agreement with, (Padhy, et al., 2016) they reported that the duration of illness of less than 5 years was detected in two third of the patients and more than 5 years in one third of the cases.

Around half of the sample of the present study have constipation prodromal, this result disagree with (Najm \& Hassan, 2016) who revealed in their study that fifty percent of the case group have diarrhea prodromal and also the result obtained from another study by (Aldamarchi, et al., 2008) who found that around half of males and female had an alternating symptoms of diarrhea and constipation.

Regarding the current study, patients had insufficient knowledge about IBS before implementing the educational module. This lack of knowledge can be due to the lack of educational services and the inaccessibility of sources of information on this disease and its effects. It represents a deficit of the provider's educational role. With regard to the level of patients of knowledge, post and follow-up implementation of an educational module, this study revealed a statistically significant improvement in all items defined.

This finding consistent with previous study by (Ringström, et al., 2009), who revealed that there was a statistically significant increase in level of knowledge for IBS patients after educational intervention compared with pre-education, which was sustained over the 12-month follow-up period.

This outcome was also consistent with (Yu et al., 2014), who confirmed that IBS patients were given an accurate description of their condition, emotional support, lifestyle (diet regimen and exercise guidance), stress management guidelines, and options for treatment, There was a substantial decrease in misconceptions related to IBS after three months of formal educational intervention, compared with the onset of the intervention.

Also, (Najm, \& Hassan, 2016) found that the differentiation between the pre and post-test for the case and control group concerning the instructional program was clear improved for the case group. The present results agree with the result obtained from another study who applied for an educational program on about two thousands of patients to correct the misconception about the prevalence of IBS and its causes by nutritional trigger, food intolerance, heredity, or a deficiency in digestive enzymes and worsens with age, they concluded that around half of patients are dissatisfied with their level of information or felt under educated.
Similarly, a study by (Flik, et al., 2015), which stated that most patients want knowledge about the diagnostic process that avoids foods, triggers, coping mechanisms, new drugs, and the importance of psychological aspect.

With regard to the severity of IBS symptoms, the current study found that, there was a significant improvement in patients' symptoms severity of IBS studied patients after pre- and post-test comparison, and the mean IBS symptom severity scores decreased significantly after the implementation of the educational module, compared with the preimplementation of the educational module. This may be due to the patients' craving to learn and practice relieving strategies to overcome this overwhelming problem that bother those patients.

In the current study it was discovered that, the majority of the patients on the total score of quality of life was determined to be $51.6 \pm 6.0$ preimplementation of educational module, compared with $68.7 \pm 8.0$ post and $76.1 \pm 11.5$ in follow-up with significant improvement was found in patients' post and follow-up phases guidelines. This may be a reflection of motivational factors and resulting from positive effect of educational intervention.

This finding is in line with those (Ghiyasvandian et al., 2016) who noticed that the application of the selfcare program led to improving quality of life and minimizing the symptom after the intervention in the study group. This also is in agreement with (Mason, 2014) who supporting patients to practice self-care and developing approved instructional materials contribute to better acceptance of the chronic nature of the disease. Effective communication between nurses and patients can contribute to better information transfer to patients and can assist them in managing self-care.

In the same line with (Ringstrom et al., 2010) showed that IBS patients with structured group training (72 subjects) compared with patients guided by a booklet ( 71 subjects) had a greater reduction in the severity of symptoms and anxiety and became more knowledgeable in IBS. Additionally, in group training, some patients experienced a significant improvement in the QoL, while QoL did not improve in another groups.

Furthermore, (Yu et al., 2014) showed that after implementation of the educational intervention, the IBS-QOL was significantly increased. Also, in accordance with (Sierżantowicz, et al., 2020), who concluded that despite long-term pharmacotherapy, the QoL for patients with IBS was substantially lower in the control group, in addition meeting patients' expectations and a varied educational therapy program culminated in a significant improvement in 
QOL for IBS patients, which resulted in a substantial reduction in the severity of symptoms. Moreover, individual learning, as well as non-pharmacological therapy, besides pharmacotherapy can be seen as a compulsory therapeutic component for patients with IBS.

In general, when we look at the habits of the patients, and when they feel any symptoms, they go to the doctor, who often prescribes treatment for them and does not have enough time to educate them about the disease. Therefore, they need awareness of how to cope with the disease symptoms.

This study showed a negative correlation between IBSQOL, and IBSSS in pre, post and follow-up phases this means a lower IBSSS score correlated with higher IBSQOL. This in agreement with (Ghiyasvandian et al., 2016) who found that there was a strong negative association $(\mathrm{p}=.01, \mathrm{r}=-.62)$ between QoL for IBS patients and the severity of IBS symptoms.

Furthermore (Torkzadeh, et al., 2019) founded in their study that the magnitude of IBS symptoms has a direct correlation with the use of maladaptive coping strategies (emotive and fatalistic) and an inverse correlation with the recruitment of positive strategies. In addition, (Björkman et al., 2019) stated that, IBS is a widespread and frequently persistent functional bowel condition that can cause major disruption to the everyday workflow among those impacted which resulted in high healthcare usage and absence from work. Finally, after analysis of data and discussion proved the research hypotheses in the current study.

\section{Conclusion:}

Patients with IBS had inadequate information about the disease and how to deal with the disease symptoms. Implantation of the educational module is effective in enhancing patients' knowledge, quality of life and decreasing the symptoms severity in IBS patients.

\section{Recommendations:}

Increase patient's awareness of the symptoms associated with IBS and the risk factors that lead to its development. Continuous patients' education should be planned regularly to control the disease symptoms and reduce its undesirable effect on the quality of life.

\section{References}

- Abd Elaziz, H., Ismail, R., Mohammed, H., \& Abd Elaziz, S. Y. (2019): Psychosocial aspects and personality dimensions among a sample of patients with irritable bowel syndrome. Egyptian Journal of Psychiatry, 40(3), 147.

- Aldamarchi, A., Muslem, U., \& AL-Yassin, A., (2008): Evaluation of Irritable Bowel Syndrom in ALDiwanyia City. Al-Qadisiyah Medical Journal, 4(6), 131-142.

- Alsuwailm, A., AL-Qahtani, M., AL-Hulaibi, A., AL-Hadi, A., Ali, I., \& Shehabeldeen, A. (2017). Irritable bowel syndrome among medical students and interns in King Faisal University. Open Journal of Preventive Medicine, 7(11), 235.

- Austin, G., Dalton, C., Hu, Y., Morris, C., Hankins, J., Weinland, S., \& Drossman, D., (2009): A very low-carbohydrate diet improves symptoms and quality of life in diarrheapredominant irritable bowel syndrome. Clinical Gastroenterology and Hepatology, 7(6), 706-708.

- Ballou, S., \& Keefer, L. (2017): Psychological interventions for irritable bowel syndrome and inflammatory bowel diseases. Clinical and translational gastroenterology, 8(1), e214.

- Björkman, I., Ringström, G., Simrén, M., Myrgren, J., \& Ung, E. J. (2019): An Intervention for Person-Centered Support in Irritable Bowel Syndrome: Development and Pilot Study. Gastroenterology Nursing, 42(4), 332-341.

- Bradley, S., Alderson, S., Ford, C., \& Foy, R. (2018). General practitioners' perceptions of irritable bowel syndrome: A Q-methodological study. Family practice, 35(1), 74-79.

- Coutts, A. (2019): Nursing management of irritable bowel syndrome. Nursing Standard, 34(5), 76-81.

- Dalrymple, J., \& Bullock, I. (2008): Diagnosis and management of irritable bowel syndrome in adults in primary care: summary of NICE guidance. Bmj, 336(7643), 556-558.

- Defrees, D., \& Bailey, J. (2017). Irritable Bowel Syndrome: Epidemiology, Pathophysiology, Diagnosis, and Treatment. Primary care, 44(4), 655-671.

- Dorn, S., Palsson, O., Woldeghebriel, M., Fowler, B., McCoy, R., Weinberger, M., \& Drossman, D. A. (2015): Development and pilot testing of an integrated, web-based self-management program for irritable bowel syndrome (IBS). Neurogastroenterology \& Motility, 27(1), 128-134.

- Drossman IV, D. A. (2016): The Rome IV Committees, editor. History of functional gastrointestinal symptoms and disorders and chronicle of the Rome Foundation. Rome IV functional gastrointestinal disorders: disorders of gut-brain interaction. I. Raleigh, NC: The Rome Foundation, 549-576. 
- Drossman, D., Patrick, D., Whitehead, W., Toner, B., Diamant, N., \& Bangdiwala, S., (2000): Further validation of the IBS-QOL: a disease-specific quality-of-life questionnaire. The American journal of gastroenterology, 95(4), 999. 1007.

- Elhosseiny, D., Mahmoud, N., \& Manzour, A. (2019): Factors associated with irritable bowel syndrome among medical students at Ain Shams University. Journal of the Egyptian Public Health Association, 94(1), 1-9.

- Flik, C., van Rood, Y., \& de Wit, N. (2015): Systematic review: knowledge and educational needs of patients with irritable bowel syndrome. European journal of gastroenterology \& hepatology, 27(4), 367-371.

- Francis, C., Morris, J., \& Whorwell, P., (1997): The irritable bowel severity scoring system: a simple method of monitoring irritable bowel syndrome and its progress. Alimentary pharmacology \& therapeutics, 11(2), 395-402.

- Ghiyasvandian, S., Ghorbani, M., Zakerimoghadam, M., Purfarzad, Z., \& Kazemnejad, A. (2016): The effects of a self-care program on the severity of symptoms and quality of life of patients with irritable bowel syndrome. Gastroenterology Nursing, 39(5), 359-365.

- Halpert, A., Dalton, C., Palsson, O., Morris, C., Hu, Y., Bangdiwala, S., ... \& Drossman, D., (2008): Patient educational media preferences for information about irritable bowel syndrome (IBS). Digestive diseases and sciences, 53(12), 31843190.

- Hoveyda, N., Heneghan, C., Mahtani, K., Perera, R., Roberts, N., \& Glasziou, P. (2009): A systematic review and meta-analysis: probiotics in the treatment of irritable bowel syndrome. $B M C$ gastroenterology, 9(1), 1-11.

- Hulisz, D. (2004): The burden of illness of irritable bowel syndrome: current challenges and hope for the future. Journal of Managed Care Pharmacy, 10(4),299-309.

- Imperatore, N., Tortora, R., Morisco, F., \& Caporaso, N. (2016): Gut microbiota and functional diseases of the gastrointestinal tract. Minerva gastroenterologica e dietologica, 63(4), 355-372.

- Lacy, B., \& Patel, N. (2017): Rome criteria and a diagnostic approach to irritable bowel syndrome. Journal of clinical medicine, 6(11), 99.

- Lovell, R., \& Ford, A. (2012): Global prevalence of and risk factors for irritable bowel syndrome: a meta-analysis. Clinical gastroenterology and hepatology, 10(7), 712-721.
- Mason, I. (2014): Supporting community patients with irritable bowel syndrome (IBS). Journal of Community Nursing, 28(1), 28-33.

- Najm, M., \& Hassan, H. (2016): Effectiveness of an Instructional Program concerning Knowledge on clients with Irritable Bowel Syndrome in Liver and Digestive Disease Hospital at Baghdad City. kufa Journal for Nursing sciences, 6(1).

- Occhipinti, K., \& Smith, J. (2012): Irritable bowel syndrome: a review and update. Clinics in colon and rectal surgery, 25(1), 46.

- Oka, P., Parr, H., Barberio, B., Black, C., Savarino, E., \& Ford, A. (2020): Global prevalence of irritable bowel syndrome according to Rome III or IV criteria: a systematic review and meta-analysis. The Lancet Gastroenterology \& Hepatology, 5(10), 908-917.

- Padhy, S. , Mishra, S., Sarkar, S., Bang, L., \& Panigrahi, M. (2016): Comparison of psychiatric morbidity in patients with irritable bowel syndrome and non-ulcer dyspepsia. Industrial psychiatry journal, 25(1), 29.

- Patel N, Shackelford K.(2020): Irritable Bowel Syndrome. [Updated Jul 10]. In: StatPearls [Internet]. Treasure Island(FL): StatPearls Available from: https://www.ncbi.nlm.nih.gov/books/NBK534810/

- Ringström, G., Störsrud, S., Lundgvist, S., Westman, B., \& Simren, M. (2009): Development of and educational intervention for patients with irritable bowel syndrome: A pilot study. BMC Gastroenterology, 9(10),1-9.

- Ringström, G., Störsrud, S., Posserud, I., Lundqvist, S., Westman, B., \& Simrén, M. (2010): Structured patient education is superior to written information in the management of patients with irritable bowel syndrome: a randomized controlled study. European journal of gastroenterology \& hepatology, 22(4), 420-428.

- Sierżantowicz, R., Lewko, J., \& Jurkowska, G. (2020). The Impact of an Individual Educational Program on the Quality of Life and Severity of Symptoms of Patients with Irritable Bowel Syndrome. International journal of environmental research and public health, 17(12), 4230.

- Sperber, A., \& Dekel, R. (2010): Irritable bowel syndrome and co-morbid gastrointestinal and extragastrointestinal functional syndromes. Journal of neurogastroenterology and motility, 16(2), 113119.

- Torkzadeh, F., Danesh, M., Mirbagher, L., Daghaghzadeh, H., \& Emami, M. (2019): Relations between coping skills, symptom severity, psychological symptoms, and quality of life in 
patients with irritable bowel syndrome. International journal of preventive medicine, 10.

- Walker, B., Colledge, R., Penman, D., \& Ralston, H. (2014): Davidsons principles and practice of medicine pp., 1588-1590.

- Weiser, K. , Lacy, B. , Noddin, L., \& Crowell, M. (2008): Patient knowledge and perspective on irritable bowel syndrome: development of a survey instrument. Digestive diseases and sciences, 53(1), 284-295.

- Yu, W., Ouyang, Y., Zhang, Q., \& Chen, J. (2014): The effectiveness of a structured educational intervention on disease-related misconception and quality of life in patients with irritable bowel syndrome. Gastroenterology Nursing, 37(4), 289-298. 